\title{
Glacier Changes and Regional Climate: A Mass and Energy Balance Approach*
}

\author{
SUMMER RUPPER \\ Department of Geological Sciences, Brigham Young University, Provo, Utah \\ GERARD RoE \\ Department of Earth and Space Sciences, and Quaternary Research Center, University of Washington, Seattle, Washington
}

(Manuscript received 6 September 2007, in final form 24 January 2008)

\begin{abstract}
The mass balance of a glacier is a complex consequence of the combination of atmospheric variables that control it. However, the understanding of past, present, and future glacier states is often predicated on very simplified representations of the mass balance-climate relationship. Here, a full surface energy and mass balance (SEMB) model is developed to explore the relationship between glacier equilibrium-line altitudes (ELAs) and climate at a regional scale. This model is applied to central Asia because of the diverse climate regimes and glacier history. The model captures the pattern in ELAs well; the seasonal cycle in energy balance terms are comparable to studies on individual glaciers in central Asia, and the proportionality factor relating melt to temperature is within the range of those reported for individual glaciers within the area. In regions where precipitation is low, ablation at the ELA is dominated by sublimation. Conversely, where precipitation is high, ablation at the ELA is dominated by melt and surface runoff. In turn, the sensitivity of the ELA to changes in climate is strongly tied to the dominant ablation process. In particular, ELAs in melt-dominated regions are most sensitive to interannual variability in air temperature, while ELAs in sublimation-dominated regions are most sensitive to interannual variability in precipitation. Glaciers in sublimation-dominated regions are acutely sensitive to even small changes in atmospheric variables. Finally, changes in clouds are shown to be important in all regions through their influence on the shortwave and longwave radiative fluxes, which dominate the surface energy balance at the ELA.
\end{abstract}

\section{Introduction}

In many parts of the world, reconstructed histories of glacier extents form the primary record of past climate changes (e.g., Porter 1977; Porter and Orombelli 1985; Gillespie and Molnar 1995; Lowell et al. 1995; Kaufman et al. 2004). Many researchers argue these histories reflect global-scale climate changes, such as the Little Ice Age and the Younger Dryas (e.g., Grove and Switsur 1994; Denton and Hendy 1994; Lowell et al. 1995; Bradley 2000). The conclusions and interpretations about such global connections in the climate system rest on

\footnotetext{
* Supplemental material related to this paper is available at the Journals Online Web site: http://dx.doi.org/10.1175/2008JCLI2219. s1.

Corresponding author address: Summer Rupper, Department of Geological Sciences, Brigham Young University, S389 ESC, Provo, UT 84602.

E-mail: summer_rupper@byu.edu
}

assumptions of how sensitively glaciers respond to characteristic climate variations.

Despite their obvious importance, there is still much ambiguity about how glaciers respond to climate. At face value, glaciers appear to be among the most straightforward natural recorders of climate: a glacier simply reflects the difference between accumulation of snow and ablation (i.e., mass loss). However, numerous environmental factors control accumulation and ablation: avalanches or wind-blown snow, rain versus snow, surface albedo variations, hillside shading, and cloudiness are just some of the examples (e.g., Paterson 1999; Kayastha et al. 1999). Moreover, if climate changes are reconstructed based on the change in a glacier's terminus position, glacier dynamics are also part of the signal.

Where glaciers within an entire region are behaving in the same way (i.e., advancing or retreating synchronously), there can be confidence that local factors specific to any single glacier are not dominating the response and that regional-scale climate variations are at 
work. In this study, we pursue this regional-scale approach.

Several methods have been employed to explore the link between glacier mass balance and climate, and at a variety of scales ranging from single glaciers and basins to whole complexes of glaciers across large regions (e.g., Braithwaite 1995; Wagnon et al. 2003; Kessler et al. 2006). The larger the spatial scale of interest, the simpler the method for estimating ablation tends to be. For example, at scales larger than a single basin, ablation is typically assumed to be proportional to some measure of summertime temperature (e.g., Fountain et al. 1999; Braithwaite et al. 2003; Oerlemans 2005). Such ablation parameterizations are appealing in their simplicity and the results from using them can be easily interpreted. However, this simplified approach to estimating ablation neglects sublimation as well as other potentially important variables such as radiation, wind speed, relative humidity, and cloudiness. The Oerlemans (2005) reconstructions of temperature from glacier length changes assume that, in the aggregate, the 169 mid- and low-latitude glaciers used in the study are responding only to changes in ablation, which is assumed to directly reflect temperature; all other atmospheric variables are neglected. This type of approach requires use of a melt factor that relates the measure of summer temperature to the ablation rate. This melt factor is an empirically determined parameter. Yet studies of different glaciers suggest melt factors vary from place to place by about a factor of up to 5 (e.g., Paterson 1999; Kayastha et al. 2003; Zhang et al. 2006).

A more physically based approach to modeling ablation is to perform a self-consistent calculation of the energy balance at the glacier surface. This has the advantage that all relevant atmospheric variables are included and that both sublimation and surface melting are a product of the calculation. Mass balance models that calculate ablation using the energy balance approach have been applied successfully to single glaciers and basins (e.g., Kayastha et al. 1999; Plummer and Phillips 2003; Molg and Hardy 2004). For example, Kayastha et al. (1999) show that a glacier in the Nepalese Himalaya is sensitive to changes in both temperature and precipitation. Energy balance studies also suggest that tropical glaciers are sensitive to subtle changes in moisture-related variables, such as cloudiness, relative humidity, and precipitation (e.g., Hastenrath 1994; Kaser et al. 2004; Molg and Hardy 2004). These examples highlight the need for a better understanding of how glacier-climate interactions vary from region to region. With this in mind, there are two questions that need to be addressed: First, can we understand the relative importance of accumulation and ab- lation in controlling the mass balance of glaciers at regional scales? Second, how do the observed patterns of glacier response reflect regional changes in climate?

This paper presents a surface energy and mass balance model that provides a framework within which to address these questions. We focus on central Asia. There are two reasons for doing so: first, glaciers are found throughout Asia in a variety of climate settings, and this allows for diverse tests of the model's abilities; second, the glacier history of central Asia is strikingly different than that of the high-latitude ice sheets (e.g., Gillespie and Molnar 1995), and we do not yet understand the mechanisms controlling these glacier changes (Rupper et al. 2007, manuscript submitted to Quat. Res., hereafter RU). This study aims to address the first-order climate controls on regional-scale glacier mass balance. The surface energy and mass balance model is able to capture the regional differences in glacier mass balance and is in agreement with observations and model studies of individual glaciers. An analysis of the energy fluxes reveals the causes of these regional differences, and sensitivity tests explore where the cause of glacier changes can be confidently understood and other regions where greater uncertainty exists.

\section{Glaciers and climate}

The equilibrium-line altitude (ELA) is defined as the altitude on a glacier where annual accumulation equals annual ablation. It is considered to be one of the most useful glaciological measures for reconstructing climate (e.g., Porter 1975; Fountain et al. 1999; Paterson 1999). All else being equal, if the ELA lowers, the glacier advances: whereas, if it rises, the glacier retreats. While other glacier characteristics such as length depend on myriad factors such as ice dynamics and bed geometry, the ELA is directly related to climate and provides a common measure whereby changes can be compared directly from one region to another.

\section{a. Central Asian glaciers}

The glacier history across central Asia has been characterized in terms of the reconstructions of paleoELAs. Gillespie et al. (2003) identify three regions that capture the spatial and temporal variability of the glaciers during the last glacial cycle. These three zones have distinctly different glacier histories, and each is different again from that of North America, Europe, Greenland, and Antarctica (Gillespie et al. 2003; RU). The three regions are shown in Fig. 1. The western zone extends from the Kyrgyz Tien Shan down to the Karakoram and into central Tibet. The northern zone in- 


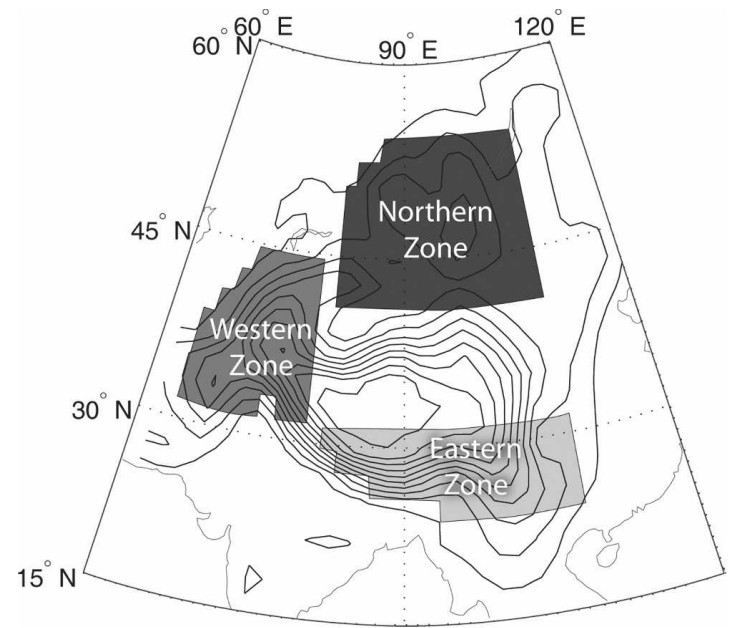

FIG. 1. Shaded areas of gray represent the general outline of the eastern, western, and northern zones, as defined by the glacier history. These are the regions over which statistics are calculated for each zone (Table 4). Contours are the NCEP-NCAR reanalysis elevations (Kalnay et al. 1996); 500-m contour interval; zero contour not shown. Coastlines are in gray.

cludes the regions of the Tien Shan in Xinjiang province, China, and the mountainous areas of central Mongolia. Finally, the eastern zone includes the portion of the Himalaya Mountains around Nepal and eastern Tibet. We demonstrate in the sections that follow that the size of each of these zones corresponds approximately to the spatial scale expected of patterns in regional climate in the modern climate. For example, there is a striking degree of temporal variability in precipitation and temperature between the three zones (Fig. 2, discussed below). It is perhaps not surprising that the glacier history also varies on these spatial scales (Gillespie and Molnar 1995; RU).

\section{b. Central Asian climate variability}

Glaciers are found on high topography throughout each of the three zones of central Asia and in very diverse climates: glaciers in the Himalayas are fed by the intense summer monsoon precipitation and a wintertime storm track; glaciers nestled along the eastern side of the Karakoram face the extreme dryness of the desert; and glaciers clinging to the peaks of the Mongolian Altai are exposed to seasonal cycles in temperature as large as $40^{\circ} \mathrm{C}$. Modern interannual climate variability can be used to explore how the sensitivity of these glaciers to climate and climate change differs across these diverse climates.

We focus first on characterizing regional variability in the modern climate, using the National Centers for Environmental Prediction-National Center for Atmospheric Research (NCEP-NCAR) reanalysis dataset
(Kalnay et al. 1996; Kistler et al. 2001). NCEP-NCAR reanalysis uses an analysis/forecast system to perform data assimilation using past data from 1948 to the present. We use the daily output available on a $2.5^{\circ}$ grid in our analyses. We consider two atmospheric quantities relevant for glaciers: total precipitation and positive degree days (PDDs-explained in the next paragraph). Topography is strongly smoothed by the coarse resolution of the reanalysis $\left(2.5^{\circ} \times 2.5^{\circ}\right)$, and thus rain at the surface elevation of a reanalysis grid point would likely not be rain at the ELA of a glacier within that grid point. We assume that all precipitation falling at the ELA is snow. A fully consistent accounting of the difference between rain and snow at the ELA would also involve calculating the refreeze of rain within the snowpack and the resulting heat input. We neglect these effects given our focus on regional scales and first-order questions. The implications for the conclusions are addressed in sensitivity studies in section 5 and in the discussion in section 6 .

PDDs are the sum of daily mean air temperatures $\left(T_{a}\right)$ that are above zero:

$$
\mathrm{PDD}=\sum H\left(T_{a}\right)
$$

where $H$ is 0 for $T_{a} \leq 0$ and $T_{a}$ for $T_{a}>0$; the sum is taken over the calendar year. Thus PDD has units of ( ${ }^{\circ} \mathrm{C}$ days). In simple treatments, total ablation is assumed to be proportional to PDDs; the constant of proportionality is known as the melt factor and is calibrated to observed melt at glaciers (e.g., Hoinkes and Steinacker 1975; Braithwaite 1995). The method is sometimes modified to include different melt factors for snow and ice and to allow for percolation and refreeze of meltwater within the snowpack (Casal et al. 2004; Zhang et al. 2006).

Figure 2 shows total annual precipitation anomalies $\left(\mathrm{mm} \mathrm{yr}^{-1}\right)$ and PDD anomalies for each year from 1948 to 2006 for each of the three zones using the NCEPNCAR reanalysis dataset (Kalnay et al. 1996). This figure highlights the differences in temporal variability between the three regions of interest. Lumping all three regions together (Fig. 2a) there is no apparent pattern. Separately, however, it is clear that each zone has different climate variability (Figs. $2 b-d$ ). The eastern zone is characteristic of monsoonal climates, having high precipitation variability and low PDD variability. The northern zone is the most continental climate, with low precipitation rates and hence low precipitation variability, contrasting with high PDD variability. In the western zone both PDD and precipitation variability is high. Thus Fig. 2 emphasizes that there are important regional differences in the climate variables that affect glaciers. 

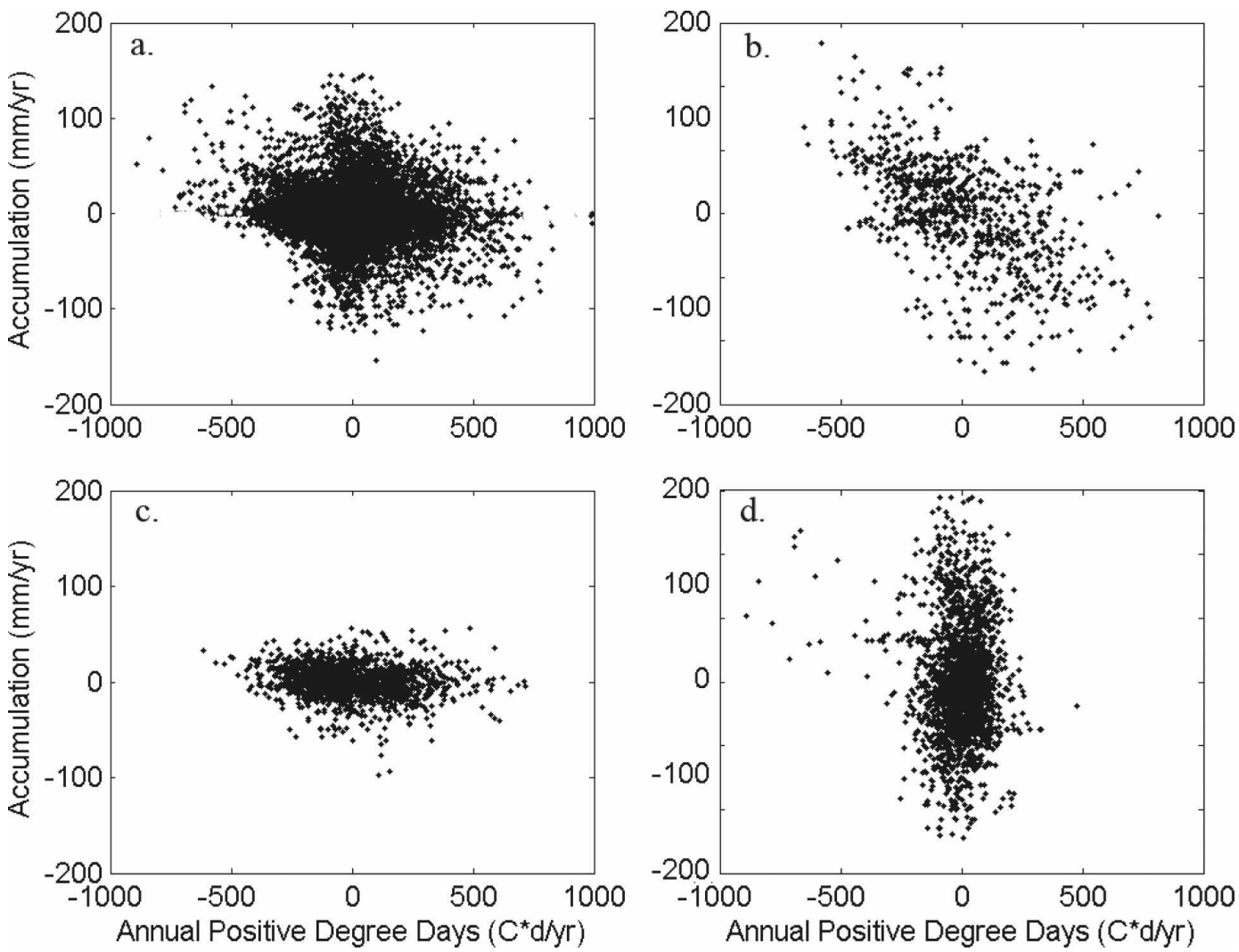

FIG. 2. Scatterplots of annual average precipitation anomalies $\left(\mathrm{mm} \mathrm{yr}^{-1}\right)$ vs positive degree day anomalies $\left({ }^{\circ} \mathrm{C}\right.$ day $\mathrm{yr}^{-1}$ ) for each grid point in the NCEP reanalysis dataset for the years 1948 to 2006. (a) central Asia, (b) the western zone, (c) the northern zone, and (d) the eastern zone. The different shape to the scatter in each region demonstrates the differences in climate variability. Means and standard deviations averaged over each of the three zones are provided in Table 4.

We next evaluate how this regional climate variability within central Asia translates into the glacier response. The following section describes the energy balance modeling framework used to achieve this.

\section{Surface energy balance and mass balance model}

We emphasize that the main goal is to understand how the ELA changes in response to climate changes. It matters less, therefore, that the modeled absolute ELA simulates the observed ELA. If the model correctly reflects the most important terms in the energy balance at the ELA, then the model can be used to evaluate the relative sensitivity of the ELA to changes in atmospheric variables. A particular strength of this approach is that, while the modeled absolute ELA is very sensitive to model parameters (i.e., albedo, surface roughness, etc.), the change in ELA for a change in climate is relatively insensitive to the magnitude of the parameters (supplemental appendix B, available online at http://dx.doi.org/10.1175/2008JCLI2219.s1).
This SEMB model has two nested balance algorithms, a surface energy balance and a mass balance. By definition, the ELA is the elevation at which these two balances both apply. For specified climate inputs, the model solves for the elevation at which a snow-covered surface would be in energy and mass balance. In other words, we ask the question "[I]f there were a glacier within a given reanalysis grid point, what would the elevation of its ELA be?"

\section{a. Surface energy balance model}

The surface energy balance model follows closely the approach taken by Kayastha et al. (1999), Wagnon et al. (2003), and Molg and Hardy (2004) but is modified such that it is suitable for application to larger regions. The basic surface energy balance equation used is

$$
Q_{m}=S+L+Q_{s}+Q_{l}+Q_{g},
$$

where $Q_{m}$ is the energy available for melting the snow/ ice surface, $S$ is the net shortwave radiation flux ab- 
TABLE 1. Model parameters and constants, their values where appropriate, and units for all equations described in section 3 and supplemental appendix A.

\begin{tabular}{|c|c|c|c|}
\hline & Parameters and constants & Value & Units \\
\hline$\alpha$ & Albedo of the glacier surface & 0.6 & \\
\hline$\sigma$ & Stefan-Boltzmann constant & $5.67 \times 10^{-8}$ & $\mathrm{~W} \mathrm{~m}{ }^{-2} \mathrm{~K}^{-4}$ \\
\hline$\varepsilon$ & $\begin{array}{l}\text { Emissivity of the glacier } \\
\text { surface }\end{array}$ & 1 & \\
\hline$C_{1}$ & Longwave emissivity constant & 0.5 to 0.9 & $\mathrm{hPa}^{-1}$ \\
\hline$c_{p}$ & $\begin{array}{l}\text { Specific heat of air at } \\
\text { constant pressure }\end{array}$ & 1010 & $\mathrm{~J} \mathrm{~kg}^{-1} \mathrm{~K}^{-1}$ \\
\hline$\rho_{o}$ & $\begin{array}{l}\text { Density of air at standard sea } \\
\text { level }\end{array}$ & 1.29 & $\mathrm{~kg} \mathrm{~m}^{-3}$ \\
\hline$p_{o}$ & $\begin{array}{l}\text { Pressure of air at standard } \\
\text { sea level }\end{array}$ & 1013 & $\mathrm{hPa}$ \\
\hline$L_{v}$ & Latent heat of vaporization & 2.514 & $\mathrm{MJ} \mathrm{kg}^{-1}$ \\
\hline$L_{s}$ & Latent heat of sublimation & 2.848 & $\mathrm{MJ} \mathrm{kg}^{-1}$ \\
\hline$L_{m}$ & Latent heat of fusion & 0.334 & $\mathrm{MJ} \mathrm{kg}^{-1}$ \\
\hline$t$ & Time & & months \\
\hline$k$ & von Kármán constant & 0.4 & \\
\hline$z$ & $\begin{array}{l}\text { Measurement level above the } \\
\text { surface of wind, relative } \\
\text { humidity, and temperature }\end{array}$ & 2 & $\mathrm{~m}$ \\
\hline$z_{\text {om }}$ & $\begin{array}{l}\text { Scalar roughness length of } \\
\text { momentum }\end{array}$ & 0.5 & $\mathrm{~mm}$ \\
\hline$z_{o h}$ & $\begin{array}{l}\text { Scalar roughness length of } \\
\text { temperature }\end{array}$ & 0.5 & $\mathrm{~mm}$ \\
\hline$z_{o v}$ & $\begin{array}{l}\text { Scalar roughness length of } \\
\text { relative humidity }\end{array}$ & 0.5 & $\mathrm{~mm}$ \\
\hline$g$ & Gravitational constant & 9.8 & $\mathrm{~m} \mathrm{~s}^{-2}$ \\
\hline$A$ & Constant & 17.67 & ${ }^{\circ} \mathrm{C}$ \\
\hline$B$ & Constant & 243.5 & ${ }^{\circ} \mathrm{C}$ \\
\hline$H$ & Scale height & 8 & $\mathrm{~km}$ \\
\hline$Z$ & Elevation & & $\mathrm{km}$ \\
\hline
\end{tabular}

sorbed at the surface, $L$ is the net longwave radiation flux, $Q_{s}$ is the sensible heat flux, $Q_{l}$ is the latent heat flux, and $Q_{g}$ is the heat conduction at the glacier surface. Since $Q_{g}$ is a small term in the seasonal energy balance (e.g., Calanca and Heuberger 1990; Kayastha et al. 1999; Ohmura 2001), it is neglected from here on. Since we assume that all precipitation falls as snow at the ELA, the heat flux supplied by precipitation is zero. All downward fluxes are positive. Tables 1 and 2 list all variables and parameters used in the equations, in the order they appear in the text. For clarity, only the main equations are discussed in the body of the text. Supplemental appendix A (available online at http://dx. doi.org/10.1175/2008JCLI2219.s1) gives a more thorough discussion of equations and parameters used.

\section{b. Shortwave radiation}

The shortwave radiation absorbed by the glacier surface, $S$, is dependent upon the incident shortwave $(S \downarrow)$ and the albedo $(\alpha)$ :

$$
S=S \downarrow(1-\alpha) .
$$

TABLE 2. List of the model variables and units used in the equations described in section 3 and supplemental appendix A.

\begin{tabular}{lll}
\hline \hline & \multicolumn{1}{c}{ Variables } & Units \\
\hline$T_{a}$ & Monthly mean air temperature at the ELA & ${ }^{\circ} \mathrm{C}$ \\
$T_{s}$ & Monthly mean surface temperature at the ELA & ${ }^{\circ} \mathrm{C}$ \\
$e_{a}$ & Evaporation vapor pressure of the air & $\mathrm{hPa}$ \\
$D_{s}$ & $\begin{array}{l}\text { Turbulent-transfer coefficient for stable } \\
\text { conditions }\end{array}$ & \\
& Pressure of air at the ELA & $\mathrm{hPa}$ \\
$e_{s}$ & Saturation vapor pressure at the surface & $\mathrm{hPa}$ \\
$T$ & Mean annual air temperature & ${ }^{\circ} \mathrm{C}$ \\
$T_{\text {amp }}$ & Amplitude in the seasonal cycle of air & ${ }^{\circ} \mathrm{C}$ \\
& $\quad$ temperature & \\
$D_{n}$ & Transfer coefficient for neutral stability & $\mathrm{m} \mathrm{s}$ \\
$v$ & Wind speed & $\mathrm{m} \mathrm{s}$ \\
$v^{*}$ & Friction velocity & \\
$\mathrm{Ri}$ & Bulk richardson number & $\%$ \\
$\mathrm{RH}$ & Relative humidity & $\mathrm{m}$ \\
$Z$ & Height of the ELA & $\mathrm{hPa}$ \\
$p_{s}$ & Pressure of air at the surface & \\
\hline
\end{tabular}

Albedo is set equal to 0.6, intermediate between that of pure ice and fresh snow (e.g., Paterson 1999). In reality albedo varies both in space and time, and it is unrealistic to know its value for all glacier surfaces across the large region of interest. However, the effect of albedo variations is evaluated in sections 5 and 6 . Since albedo is held fixed, variability in absorbed shortwave radiation in the model is governed only by variability in cloudiness.

\section{c. Longwave radiation}

Net longwave radiation is equal to the sum of the outgoing and incoming longwave radiation,

$$
L=L \uparrow+L \downarrow .
$$

Here $L \uparrow$ is calculated using the Stefan-Boltzmann law

$$
L \uparrow=\sigma \varepsilon_{s} T_{s}^{4}
$$

and is therefore a function only of the surface temperature $\left(T_{s}\right)$. Emissivity $\left(\varepsilon_{s}\right)$ of the snow/ice surface is assumed to be equal to one and $\sigma$ is the Stefan-Boltzman constant: $L \downarrow$ is controlled largely by the air temperature above the surface but is also dependent on radiative properties of the atmosphere itself, especially atmospheric relative humidity and clouds.

There are many empirical formulas employed to calculate incoming longwave radiation. We follow the equation suggested by Duguay (1993)

$$
L \downarrow=\sigma T_{a}^{4}\left(C_{1}+C_{2} e_{a}\right),
$$

where $T_{a}$ and $e_{a}$ are the near-surface ( $\left.2 \mathrm{~m}\right)$ air temperature and vapor pressures, respectively. To test the sen- 
sitivity of the results to assumptions in the longwave calculation, the constants $C_{1}$ and $C_{2}$ were determined in two different ways: First, they were assumed to be equal to the average reported for individual glaciers, 0.55 and 0.017, respectively (e.g., Duguay 1993; Molg and Hardy 2004). The contribution from $C_{2} e_{a}$ was typically less than $5 \%$, and so is neglected. This suggests that relative humidity is not as important as other radiative properties, such as clouds. For the second method, used for the standard case presented here, the monthly mean $C_{1}$ is determined using the NCEPNCAR incoming radiation at the surface, which yields similar values to Duguay (1993). This calibrated $C_{1}$ is therefore the emissivity of the lower troposphere in the longwave band and is therefore dependent on temperature, cloudiness, etc. Both methods for calculating $C_{1}$ and $C_{2}$ yielded similar results.

\section{d. Sensible and latent heat fluxes}

A commonly employed method for calculating turbulent heat fluxes is the so-called bulk method based on the Monin-Obukhov similarity theory. For sensible heat,

$$
Q_{s}=D_{s} c_{p} \rho_{o} \frac{p}{p_{o}}\left(T_{a}-T_{s}\right), \text { where }
$$

$T_{s}$ and $T_{a}$ are the surface temperature and near-surface air temperature; $c_{p}$ is the specific heat at constant pressure; $\rho_{o}$ is the density of air at sea level; $D_{s}$ is the turbulent transfer coefficient, dependent upon wind speed, roughness lengths, and a correction for buoyant versus mechanical mixing; and $p / p_{o}$ is the atmospheric pressure at the ELA divided by atmospheric pressure at standard sea level. This reflects that the atmosphere's ability to carry heat is dependent on its density.

For latent heat,

$$
Q_{l}=D_{s} \rho_{o} \frac{1}{p_{o}} L_{v, s}\left(e_{a}-e_{s}\right) .
$$

If the surface temperature is zero or above, then the latent heat of vaporization $\left(L_{v}\right)$ is used, while if it is below zero, than for sublimation $\left(L_{s}\right)$ is used: $e_{s}$ is the vapor pressure at the surface, which is assumed to be saturated and so $\mathrm{e}_{\mathrm{s}}$ depends only on the $T_{s} ; e_{a}$ is the vapor pressure of the above surface air and depends on both $T_{a}$ and relative humidity. Therefore the latent heat flux is a function of $T_{a}, T_{s}$, and relative humidity.

\section{e. Mass balance and seeking the ELA}

To facilitate discussion of the algorithms used to solve for the ELA, one more constraint from the reanalysis data needs to be addressed. The ELA is an annual mean property. To close the equations and obtain a unique value for the ELA, the relationship between the temperatures at each time step in the annual cycle must be prescribed:

$$
T_{a}=\bar{T}(z)+T_{\mathrm{amp}} \cos \left(2 \pi \frac{t}{12}\right),
$$

and $\bar{T}$ is the mean annual 2-m air temperature at the ELA, with $\bar{T}$ being a function of the height $z$ of the ELA. The amplitude of the annual cycle in air temperature, $T_{\mathrm{amp}}$, is prescribed using the reanalysis output. We use monthly time steps in what is presented here. Several calculations were made using daily time steps, but this did not substantially change the results.

The surface energy balance and mass balance models are combined to solve for the ELA. The energy balance portion of the model calculates the energy available for melt $\left(Q_{m}\right)$ every month from (2), following the method of Kayastha et al. (1999). Using an iterative solver, $T_{s}$ converges toward a value such that all fluxes are balanced (i.e., $Q_{m}$ is equal to zero). If the resulting $T_{s}$ is greater than zero, then $T_{s}$ is reset to zero and $Q_{m}$ is recalculated. This recalculated $Q_{m}$ represents the energy available for melt. Melt is then equal to $L_{m}^{-1} Q_{m}$ for months where $T_{s}$ equals $0^{\circ} \mathrm{C}$. Additionally, evaporation occurs when $T_{s}$ equals $0^{\circ} \mathrm{C}$ and $e_{a}<e_{s}$ and is calculated as $L_{v}^{-1} Q_{l}$. When $T_{s}$ is less than $0^{\circ} \mathrm{C}$ and $e_{a}<e_{s}$, sublimation occurs at a rate of $L_{s}^{-1} Q_{l}$. The total ablation per month is then the sum of the monthly sublimation, evaporation, and melt.

In the mass balance iterative algorithm, the model seeks the elevation at which the $\bar{T}$ results in a total annual ablation (calculated using the surface energy balance method above) that exactly equals the total annual accumulation. In the mass balance portion of the model, the $\bar{T}$ is sought for which ablation equals accumulation. Once this $\bar{T}$ is found, the climatological lapse rate is applied to determine the elevation of the ELA relative to the surface of the reanalysis grid point. The final model output includes monthly $2-\mathrm{m}$ air temperature, surface temperature, all energy balance terms, sublimation, melt, and evaporation at the equilibrium line for a given set of climate variables and model parameters.

\section{Surface energy balance and mass balance model results}

We briefly recap the procedure. The basic goal is to characterize how regional patterns of climate variability translate into regional patterns of ELA sensitivity. Taking NCEP-NCAR reanalysis output, we ask the question "[I]f there were a glacier within a given reanalysis grid point, what would the elevation of its ELA be?" In 


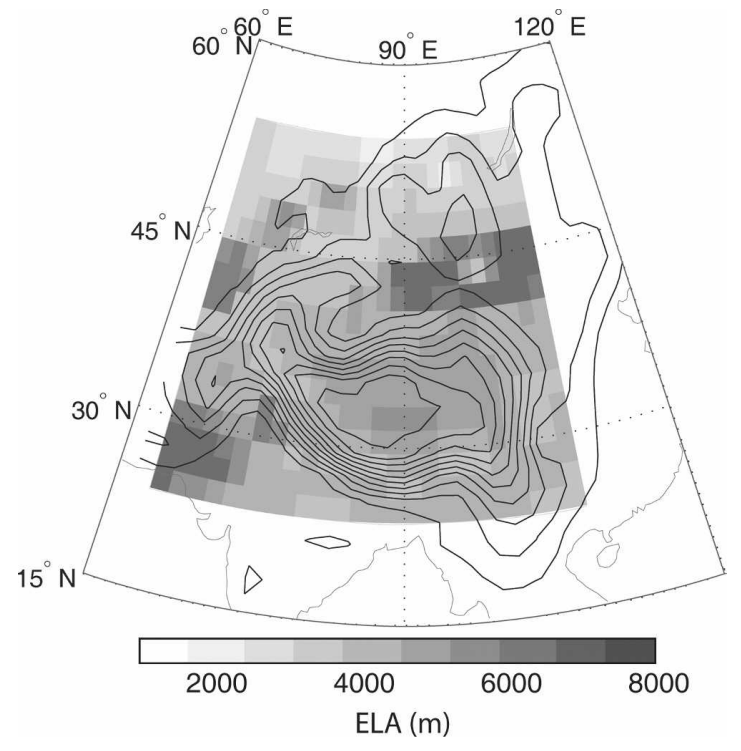

FIG. 3. Colors are the elevation $(\mathrm{m})$ of the equilibrium line calculated using the SEMB model; 500-m contour interval; zero contour not shown. Coastlines are in gray.

other words, using the SEMB model we solve for the elevation at which a snow-covered surface would be in mass and surface energy balance.

\section{a. Equilibrium-line altitudes}

The pattern in the ELAs calculated from the NCEPNCAR climatology using the SEMB model is shown in Fig. 3. Despite the coarse resolution of the reanalysis output and the uncertainty in model parameters, the general pattern in the modeled ELAs is reasonable. Figure 4 a shows a high-resolution digital elevation model (DEM) with colors marking peaks that would intersect the modeled ELAs. Glaciers are likely to exist where the ELA intersects topography. Figure 4b shows the same DEM and ELA intersection, but with pink dots marking actual glaciers (Raup et al. 2007). The biggest discrepancy is that the model predicts more extensive glaciers than observed in the interior of the plateau. This is perhaps due to the coarse resolution of the NCEP-NCAR climatology, which allows for greater penetration of the monsoonal rains over the Tibetan Plateau. There are also too few glaciers in the northern zone. This is also likely due to the coarse resolution and uncertainty in the magnitude of precipitation in the region. We emphasize that our primary interest is in how patterns in climate change lead to patterns of ELA change, so we are less interested in simulating the climatological mean ELA. However, it is at least reassuring that the SEMB model reproduces broadly where glaciers are found in the current climate.

\section{b. Sublimation or melt?}

One of the advantages of applying a self-consistent surface energy balance approach is the ability to assess the relative importance of sublimation and melt in the ablation process. The fractional contribution of melt to the total ablation at the ELA calculated from the NCEP-NCAR climatology is shown in Fig. 5. There are places where ablation occurs almost entirely by melt and others by sublimation. In particular, a qualitative comparison of the pattern in the fractional contribution of melt (Fig. 5) to the spatial pattern in annual average precipitation (Fig. 10a) indicates that, at the ELA, melt dominates where precipitation is high and sublimation dominates where precipitation is low.

The relationship between the ablation pattern and precipitation pattern is highlighted in Fig. 6. The scatterplot shows that melt dominates regions where precipitation is greater than $\sim 0.5 \mathrm{~m} \mathrm{yr}^{-1}$ and sublimation dominates in regions where precipitation is less than $\sim 0.25 \mathrm{~m} \mathrm{yr}^{-1}$. The shapes around the dots in Fig. 6 represent the three different zones. These shapes highlight the regions dominated by sublimation and those that are dominated by melt. In particular, the eastern zone is entirely dominated by melt at the ELA. Both the western and northern zones include regions of dominantly melt and sublimation. The reason for the general relationship between ablation and precipitation can be seen from a comparison of the seasonal cycle in the surface temperature and energy balance (discussed below). The rapid transition between melt and sublimation is discussed further in section 6 .

\section{c. Seasonal cycle in climate and energy balance terms}

We contrast the surface energy and mass balances at the ELA for two reanalysis grid points, one in the meltdominated region and one in the sublimationdominated region. The two points are denoted by $\mathrm{A}$ and B, respectively, in Fig. 5. Importantly, the results discussed for points $\mathrm{A}$ and $\mathrm{B}$ are not unique to those points; the results are similar for the other grid points in melt- and sublimation-dominated regions.

First, for gridpoint $\mathrm{A}$ in the melt-dominated region, the total precipitation is $3.5 \mathrm{~m} \mathrm{yr}^{-1}$ and peaks strongly during the summer monsoon (Fig. 7, top panel). To melt this depth of ice takes a flux of approximately $\sim 50$ $\mathrm{W} \mathrm{m}{ }^{-2}$ averaged over the year. In contrast, because the energy required to sublimate is 8.5 times greater than that to melt, it would require approximately $\sim 425 \mathrm{~W}$ $\mathrm{m}^{-2}$ to sublimate the total accumulation. It is therefore much more efficient for the system to melt the $3.5 \mathrm{~m}$ $\mathrm{yr}^{-1}$. At the ELA, in order to balance this amount of 

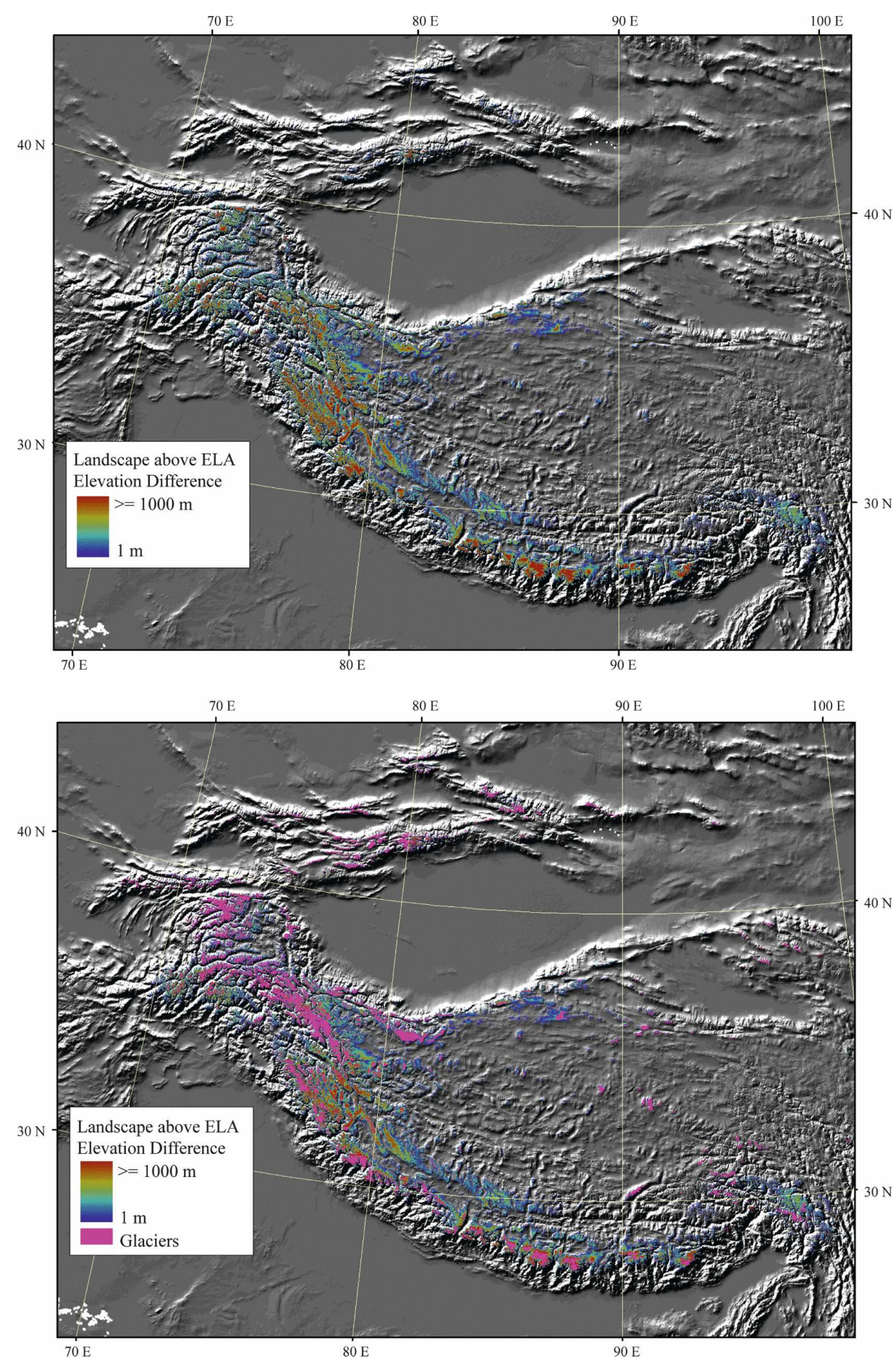

FIG. 4. Grayscale is a high-resolution DEM of central Asia. Colored shading from blue to red highlights those regions where and by how much the topography intersects the modeled ELAs. (lower) Locations of actual glaciers are highlighted in pink. This is not intended to be a test of the model skill.

accumulation, the SEMB model determines that the surface temperature must be equal to $0^{\circ} \mathrm{C}$ for approximately five months (i.e., the length of the melt season), shown in the top panel of Fig. 7. Therefore the annual- mean surface temperature at the ELA must be higher, and the resulting ELA is lower.

The seasonal cycle of the various energy fluxes are shown in the bottom panel of Fig. 7. For the 5-month 


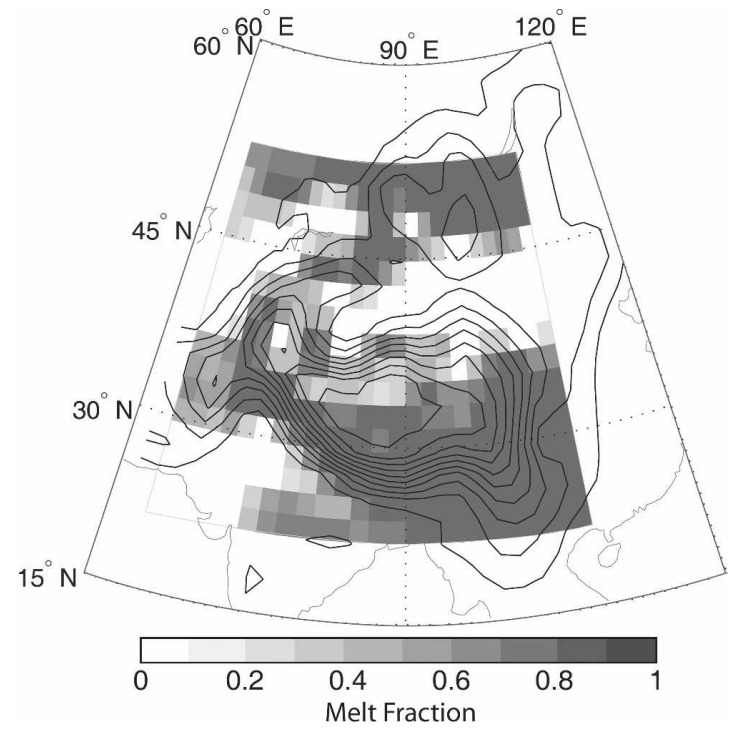

FIG. 5. Fractional contribution of melt to the total ablation, at the ELA. Output is from the surface energy balance and mass balance model. White areas are regions where sublimation accounts for the total ablation; gray regions are melt-dominated areas; 500-m contour interval; zero contour not shown. Coastlines are in gray. Note the spatial pattern in dominant ablation mechanisms across the region. This pattern is reminiscent of the pattern in annual average precipitation (Fig. 10a). Points A and B denote grid points where seasonal cycles in climate and energy balance terms are presented in Figs. 7 and 8.

period for which $T_{s}=0$, there is an imbalance in the energy fluxes, which provides the excess energy available for melt. This energy flux used for melting is approximately equal to the difference between net shortwave and net longwave radiation fluxes. These three terms dominate the energy balance throughout the year. The turbulent sensible and latent heat fluxes are small in comparison to the radiative fluxes. During the seven months of the year for which melt does not occur, the turbulent latent heat flux is negative, implying sublimation; overall, however, melt accounts for $99.5 \%$ of the total annual ablation. These results are summarized in Table 3 with values of the energy balance components averaged over the melt season and sublimation season separately.

The seasonal cycle and seasonal averages of the energy balance terms compare well with studies on individual glaciers in melt-dominated regions of central Asia (e.g., Calanca and Heuberger 1990; Kayastha et al. 1999). These studies also show that melt dominates in regions where precipitation is high and that the radiative fluxes dominate the energy balance at the surface.

The dominance of radiative fluxes throughout the year at gridpoint A (Fig. 7b, Table 3), and in all regions where melt dominates, suggests that the ELA in melt- dominated regions will be most sensitive to climate variables that control the radiative fluxes-cloudiness, air temperature, surface temperature, and the longwave constant $\left[C_{1}\right.$ in (6) $]$-rather than variables affecting the turbulent heat fluxes, such as relative humidity and wind speed. In contrast, at gridpoint $\mathrm{B}$, where sublimation dominates, the total annual precipitation is extremely low, approximately $15 \mathrm{~cm} \mathrm{yr}^{-1}$ (Fig. 8, top panel). This takes a flux of only $\sim 2 \mathrm{~W} \mathrm{~m}^{-2}$ to melt. By comparison sublimating the same amount of mass would consume $\sim 16 \mathrm{~W} \mathrm{~m}^{-2}$. With such low accumulation rates, melting cannot dominate the mass balance at the ELA. Sublimation occurs whenever the temperature is below $0^{\circ} \mathrm{C}$ and the turbulent latent heat is negative. Typical seasonal cycles in surface temperature mean that, if, even for a short while, the temperature touches $0^{\circ} \mathrm{C}$ at any time during the year, the sublimation happening in the nonmelt season (i.e., the rest of the year) is already more than enough to ablate the available accumulation. Therefore the annual-mean surface temperature at the ELA must be lower, and the ELA must be higher.

Figure 8 (bottom panel) shows how this operates at point B. Annual-averaged values of the separate energy components are in Table 3. Averaged over the annual cycle, the net solar radiation is $90 \mathrm{~W} \mathrm{~m}^{-2}$. This is chiefly balanced by the net longwave radiation $\left(-63 \mathrm{~W} \mathrm{~m}^{-2}\right)$. Making up the balance is the sensible heat flux $(-11 \mathrm{~W}$ $\left.\mathrm{m}^{-2}\right)$, and latent heat flux $\left(-16 \mathrm{~W} \mathrm{~m}^{-2}\right)$. This latent heat flux suffices to sublimate the accumulation and so achieve mass balance. This picture agrees with studies on tropical glaciers. Particularly where accumulation rates and the seasonal cycles in air temperature are low, sublimation will come to dominate the mass balance (e.g., Wagnon et al. 2003; Molg and Hardy 2004). In addition to atmospheric variables affecting the radiation balance, and unlike melt-dominated regions, relative humidity and wind speed are likely to be important controls on the ELA because these variables influence the turbulent latent heat flux, which supplies all energy for sublimation.

These results, the reasonable pattern in ELAs and the agreement with observations made at particular field sites, all suggest that the SEMB model is performing well and is capable of capturing the sensitivity of ELAs to a change in climate at a regional scale.

\section{d. Comparison with positive degree-days}

The constant of proportionality relating PDDs to ablation is known as the melt factor, which is typically an empirically derived parameter. A particular strength of the SEMB approach is that the melt factors can be calculated directly since both the seasonal cycle in near- 


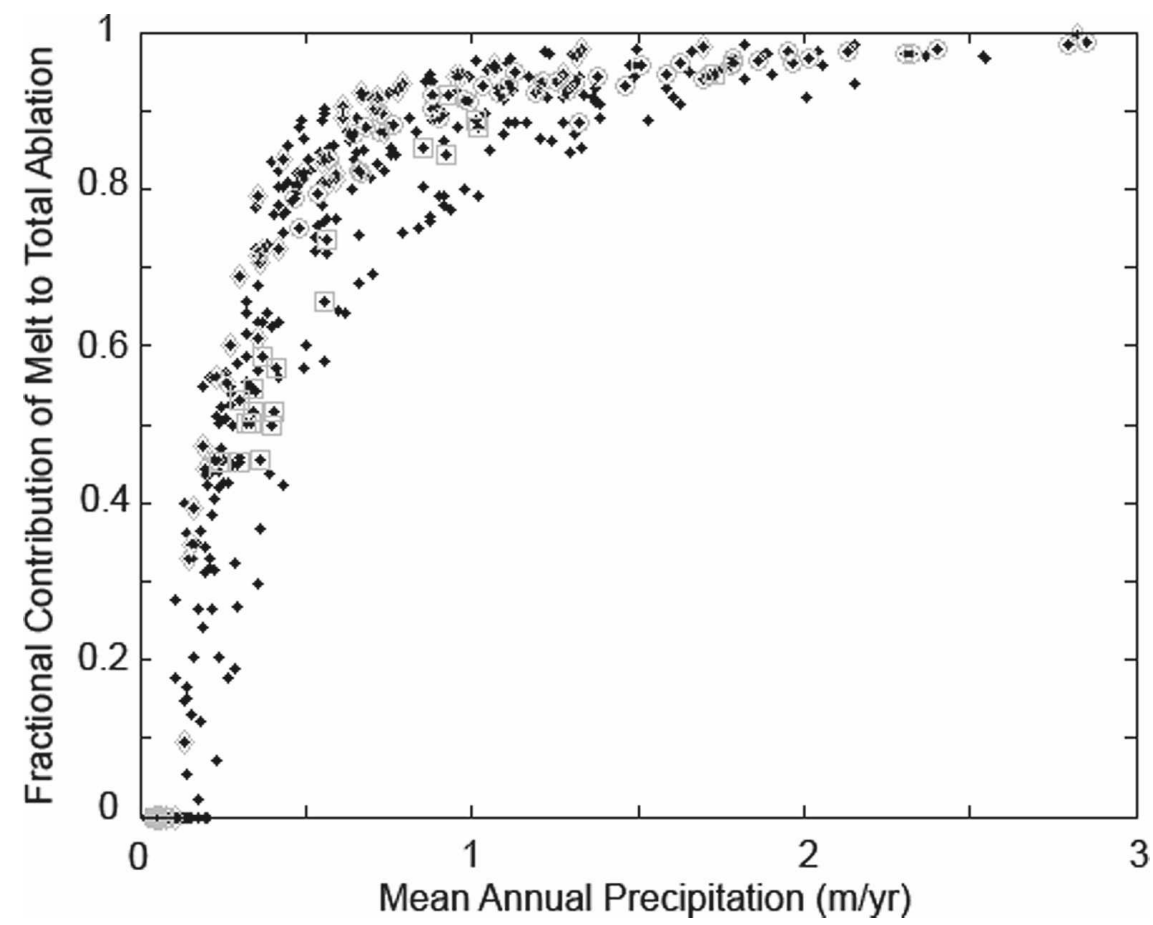

FIG. 6. Mean annual precipitation vs fractional contribution of melt to total ablation at each NCEP-NCAR reanalysis grid point across central Asia. Shapes highlight those points that fall within the three zones: eastern zone (circles), western zone (squares), and northern zone (diamonds).

surface air temperature and melting are outputs from the model.

Figure 9 shows histograms of the melt factors calculated within the three regions for grid points at which PDDs exceed zero at the ELA. Melt factors vary between approximately 5 and $18 \mathrm{~mm}$ day ${ }^{-1}{ }^{\circ} \mathrm{C}^{-1}$ for all of central Asia, with the mean equal to $11 \mathrm{~mm}$ day $^{-1}{ }^{\circ} \mathrm{C}^{-1}$. The mean for the western, northern, and eastern zones are 12,9 , and $10 \mathrm{~mm}$ day $^{-1}{ }^{\circ} \mathrm{C}^{-1}$, respectively. While there is both regional variability and a sizable spread in melt factors across the region, the values agree well with those measured in the area. For example, Nepalese and Chinese researchers have measured the melt factors in the southern Himalayas and the Tien Shan and report melt factors ranging between 5 and $16 \mathrm{~mm}$ day ${ }^{-1}{ }^{\circ} \mathrm{C}^{-1}$ (e.g., Kayastha et al. 2003; Zhang et al. 2006).

The comparison of melt factors from the SEMB model and the empirically determined coefficients gives two pieces of information. First, the general approximate agreement between the SEMB-derived melt factors with observations suggests that the SEMB model is calculating realistic ablation rates, given the large-scale forcing. Next, there is no fundamental reason why the melt factor should be constant in space or time. However, studies that use the PDD method on a regional scale have to make that assumption. Second, the histograms in Fig. 9 give a sense of how melt factors actually vary in space and suggests care be taken if the magnitude of the answer being sought would lie within the range of uncertainty suggested by Fig. 9 .

To this point we have shown that regional patterns in climate give rise to regional patterns in both ELAs and the dominant ablation mechanisms. From these results it follows that regional patterns in glacier ELA sensitivity to changes in climate should be expected as well.

\section{Spatial patterns of glacier sensitivity}

The SEMB model can be used to explore the sensitivity of ELAs to climate variability. The measure of climate variability that we use is one standard deviation of the interannual variability of an atmospheric variable, within each reanalysis grid point. This creates a common measure of characteristic variability for each atmospheric variable.

Figures $10 \mathrm{a}$ and $10 \mathrm{~b}$ show the mean annual precipitation and standard deviation $(\sigma P)$ from the reanalysis output, and averages in each of the three zones are given in Table 4. The regional patterns of mean and standard deviation are quite similar.

The change in the $\triangle$ ELA for a change in precipita- 

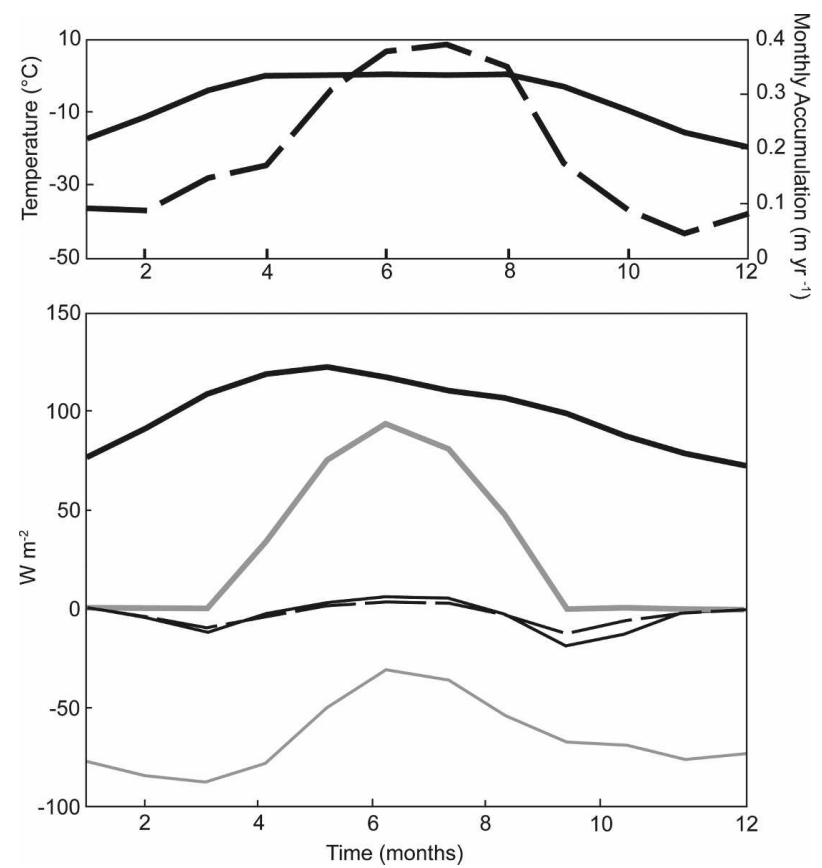

FIG. 7. Seasonal cycle in climate and energy balance components at gridpoint A (Fig. 5) in a melt-dominated region. (top) The seasonal cycle at the modeled ELA in surface temperature (solid) and total monthly precipitation (dashed). (bottom) The seasonal cycle in net shortwave radiation (bold black), net longwave radiation (thin gray), turbulent sensible heat flux (thin black), turbulent latent heat flux (dashed black), and excess energy flux available for melt (bold gray) at the modeled ELA. Incoming fluxes are positive.

tion equal to $\sigma P$ is calculated at each grid point across the model domain. In other words, $\triangle E L A$ is equal to the ELA for $P$ plus $\sigma P$ minus the ELA for $P$. (Note that the results below are similar when $\triangle E L A$ is calculated for a decrease in precipitation equal to $\sigma P$.) The response of glacier ELAs is striking (Fig. 10c). It is not a simple function of the magnitude of $\sigma P$. In particular, sublimation-dominated regions are acutely sensitive to even small changes in precipitation. This is despite the fact that the standard deviation in precipitation in the sublimation regions is much less than in the melt regions (Fig. 10b, Table 4). For example, the average change in $\triangle \mathrm{ELA}$ in the northern zone, a region dominated by sublimation, is $550 \mathrm{~m}$ for $\sigma P=0.1 \mathrm{~m} \mathrm{yr}^{-1}$. By comparison, in the melt-dominated region of the eastern zone, the average change in $\triangle$ ELA is only $130 \mathrm{~m}$ for $\sigma P=0.7 \mathrm{~m} \mathrm{yr}^{-1}$. Thus the sensitivity of the ELA to a change in precipitation depends on the dominant ablation process and the mean annual precipitation. In sublimation-dominated regions, the change in ELA is large even in regions where mean annual precipitation is low. The difference in the sensitivity of ELAs to changes in precipitation between the sublimation and melt regions arises because of the large difference between the latent heat of sublimation and that of melt. While sublimation regions are clearly most sensitive to changes in precipitation, the pattern in $\Delta$ ELAs within melt and sublimation regions strongly resembles the pattern in the $1 \sigma$ precipitation (Figs. 10b,c) with the largest changes in ELAs occurring where precipitation changes are also greatest.

As in the case with precipitation, the sensitivity of the ELAs to changes in relative humidity and wind speed also changes depending on the dominant ablation process (Table 4). $\triangle$ ELAs for a sigma change in relative humidity and wind are small in all regions. However, sublimation-dominated regions are more sensitive to changes in relative humidity and wind than meltdominated regions. These results highlight the fact that sublimation-dominated regions are generally more sensitive to even small changes in climate than meltdominated regions are. It is important to note that, for a change in climate, larger changes in relative humidity might be possible. Also, the energy fluxes are nonlinear combinations of atmospheric variables and day-to-day fluctuations in relative humidity are much greater than the interannual variability. These variations will not necessarily average to the monthly values. This suggests

TABLE 3. Mean values of the energy balance components, total accumulation (which equals total ablation at the ELA), and fractional contribution of melt to total ablation for the 5-month melt season at point A, 7-month sublimation season at point A, and all 12 months at point $\mathrm{B}$.

\begin{tabular}{|c|c|c|c|c|}
\hline \multirow[b]{2}{*}{ Energy balance component or ablation } & \multirow[b]{2}{*}{$\begin{array}{c}\text { Point A } \\
\text { (12 months) }\end{array}$} & \multirow[b]{2}{*}{$\begin{array}{c}\text { Melt season at } \\
\text { point A (5 months) }\end{array}$} & \multicolumn{2}{|c|}{ Sublimation season at } \\
\hline & & & $\begin{array}{l}\text { Point A } \\
\text { (7 months) }\end{array}$ & $\begin{array}{c}\text { Point B } \\
\text { (12 months) }\end{array}$ \\
\hline Total ablation/total accumulation $\left(\mathrm{m} \mathrm{yr}^{-1}\right)$ & 3.5 & & & 0.15 \\
\hline Net shortwave radiation $\left(\mathrm{W} \mathrm{m}^{-2}\right)$ & & 100 & 88 & 90 \\
\hline Net longwave radiation $\left(\mathrm{W} \mathrm{m}^{-2}\right)$ & & -53 & -81 & -63 \\
\hline Turbulent latent heat flux $\left(\mathrm{W} \mathrm{m}^{-2}\right)$ & & 1 & -3 & -16 \\
\hline Turbulent sensible heat flux $\left(\mathrm{W} \mathrm{m}^{-2}\right)$ & & 2 & -4 & -11 \\
\hline Latent energy flux for melting $\left(\mathrm{W} \mathrm{m}^{-2}\right)$ & & 40 & 0 & 0 \\
\hline Fractional contribution of melt to total ablation & 99.5 & & & 0 \\
\hline
\end{tabular}



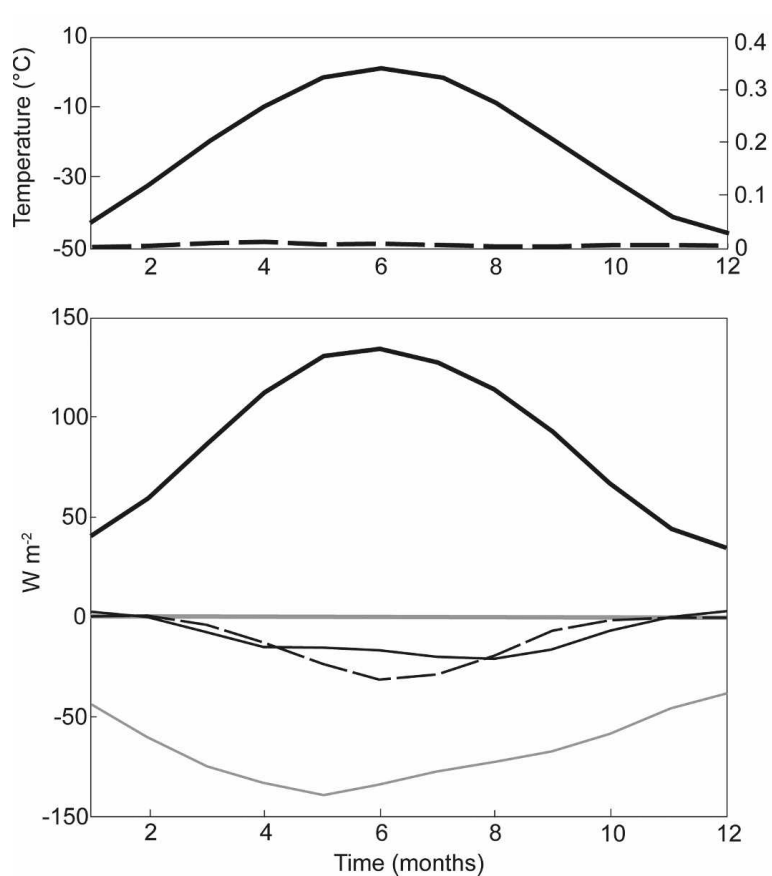

FIG. 8. As in Fig. 7 but for grid point B (Fig. 5) in a sublimation-dominated region.

that sublimation regions are likely to be sensitive to assumptions in the formulation of the SEMB model.

Interannual changes in shortwave radiation incident at the surface are due to changes in cloudiness. Thus $\triangle E L A$ for a one standard deviation increase in absorbed shortwave radiation is a test of the sensitivity of the ELA to the influence of clouds on incoming shortwave radiation. The sensitivity of ELAs to a one standard deviation change in shortwave radiation is nearly uniform across central Asia (Table 4), but is of secondary importance to typical interannual variability in precipitation in all regions.

The sensitivity tests to changes in individual variables clearly demonstrate that a one standard deviation change in different climate variables results in spatial patterns in ELA changes. However, radiation effects on ELAs, such as the changes in solar radiation, cannot be completely decoupled in this model because we prescribe the seasonal cycle in air temperature $\left(T_{\text {amp }}\right)$ using reanalysis output. This is necessary to get a unique solution for the annual average air temperature at the ELA. So, for example, if a change in clouds leads to a change in $T_{\mathrm{amp}}$, that dependency is not factored in the sensitivity analysis.

An alternative to perturbing individual climate variables is to composite atmospheric variables for years when mean summer, June-August (JJA), air temperatures are anomalously warm (chosen here to be those

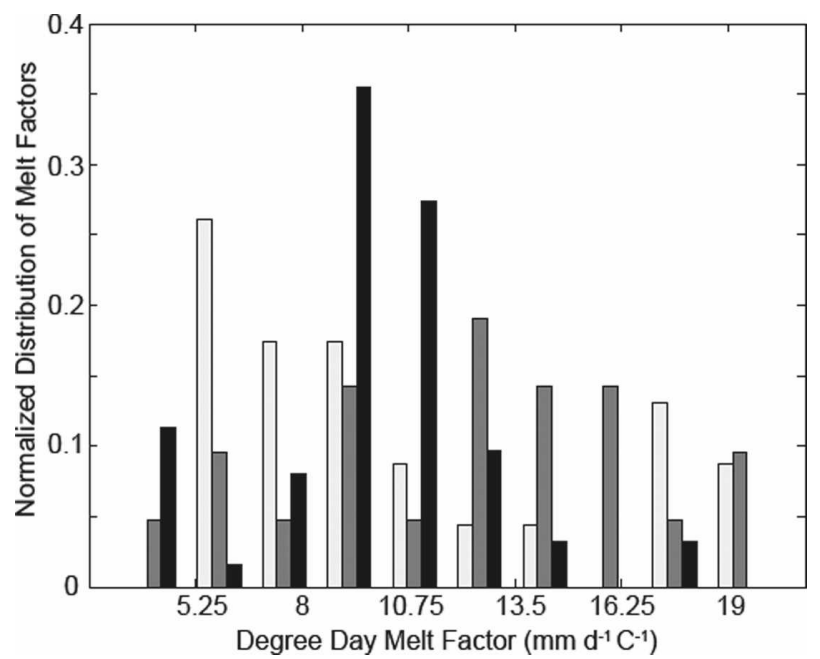

FIG. 9. Normalized distribution of melt factors for positive degree days, calculated using the SEMB model, across the western (dark gray), northern (light gray), and eastern (black) zones. Mean melt factors for the western, northern, and eastern zones are 12,9 , and $10 \mathrm{~mm} \mathrm{day}^{-1}{ }^{\circ} \mathrm{C}^{-1}$, respectively.

exceeding one standard deviation above the mean) at each grid point. In this case, $\triangle E L A$ is calculated as the ELA for the average of years with anomalously warm summers minus the ELA for all years. Changes in ELAs for anomalously warm summers provide a test of the ELA sensitivity to changes in ablation. The relative contribution of different variables to the anomalous warmth can then be evaluated separately as well. (Note that the results below are similar when $\triangle E L A$ is calculated for anomalously cool summers.)

The variables examined in the composite analysis are incident shortwave radiation, relative humidity, wind speed, atmospheric pressure, incoming longwave constant $\left(C_{1}\right)$, lapse rate in air temperature, and the amplitude in the seasonal cycle $\left(T_{\text {amp }}\right)$. The mean summer air temperature, $\sigma T_{a}$, and $\triangle$ ELA for the anomalously warm summers are shown in Fig. 11. Averages over the northern, western, and eastern zones are presented in Table 4. Figure 11c highlights the result that a pattern in $\triangle$ ELA occurs in response to conditions during years when summer air temperatures are anomalously warm, with the largest change in ELA generally in regions where $\sigma T_{a}$ is largest. Importantly, melt-dominated regions are far more sensitive to interannual variability in summer temperature than in precipitation. In particular, $\triangle$ ELAs for a change in temperature are approximately twice that for changes in precipitation. In contrast, ELAs in sublimation-dominated regions are more sensitive to interannual variability in precipitation than in temperature. 

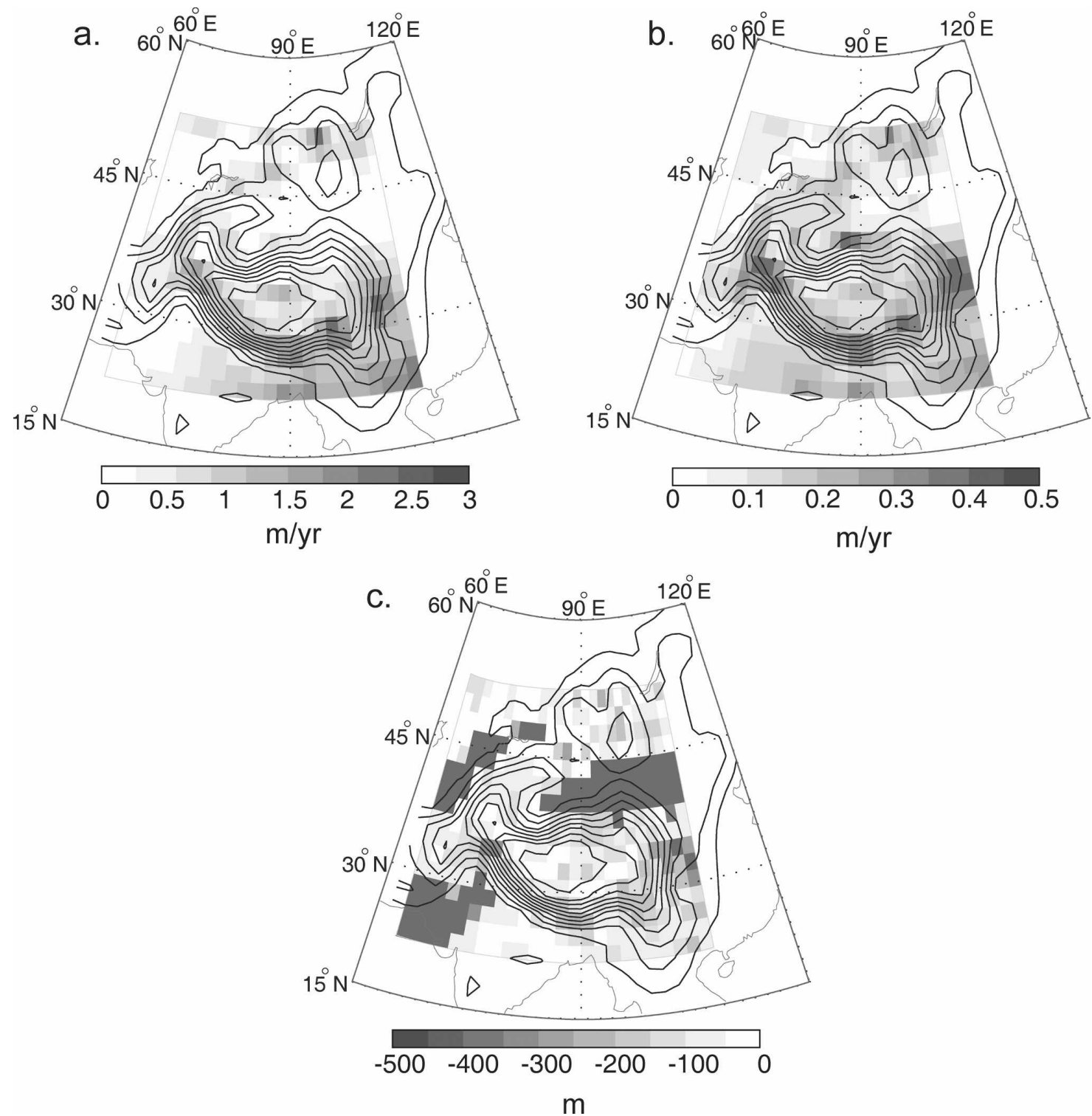

FIG. 10. (a) Mean annual precipitation $\left(\mathrm{m} \mathrm{yr}^{-1}\right)$, (b) standard deviation in annual precipitation $\left(\mathrm{m} \mathrm{yr}^{-1}\right)$, and (c) $\Delta \mathrm{ELA}$ for one standard deviation increase in precipitation $(\mathrm{m})$. Changes less than $-500 \mathrm{~m}$ are saturated; 500 - $\mathrm{m}$ contour interval; zero contour not shown. Coastlines are in gray.

In detail, there are regions where this general relationship between ELAs and temperature does not necessarily hold. For example, in the far eastern zone the standard deviation in air temperature is relatively small while the change in ELA is large. The sensitivity of the ELAs to changes in air temperature is the result of the sensitivity of the ELAs to the changes in each of the variables composited over anomalously warm summers. The sensitivity of the ELA to the composited variables is discussed in more detail below. Sensitivity tests suggest that incident shortwave radiation, $C_{1}$, and $T_{\mathrm{amp}}$ have the greatest influence on changes in ELAs during anomalously warm or cold years. We therefore focus discussion on those three variables.

Changes in shortwave radiation and $C_{1}$ are driven by changes in cloudiness (Figs. 12b-d). In particular, an increase in clouds has a tendency to warm the climate through an increase in incoming longwave radiation (increase in $C_{1}$ ) and cool the climate through a decrease in shortwave radiation (increased albedo). The changes in cloudiness in the NCEP reanalysis output show that, in some regions, the influence of clouds on the longwave radiation tends to be greater than the decreased albedo, thereby causing a net warming when cloud frac- 
TABLE 4. All values are the mean for the eastern, western, and northern zones (Fig. 1). The table includes the mean ELA (m) and melt contribution to total ablation (fraction) at the ELA. Also included in the table are the mean and standard deviation $(\sigma)$ in annual precipitation $(P)$, summertime solar insolation $(S)$, summertime wind speed $(V)$, summertime relative humidity (RH), and summertime air temperature $\left(T_{a}\right)$. Summertime is the mean for June-August. The change in ELA for one standard deviation changes in $P, S, V$, and $\mathrm{RH}$ is also shown. The change in ELA for changes in all atmospheric variables composited over years when mean summertime temperatures are one standard deviation above the mean is also included.

\begin{tabular}{llccc}
\hline \hline & Units & East & West & North \\
\hline Modeled ELA & $\mathrm{m}$ & 4880 & 4625 & 4648 \\
Melt fraction & - & 0.85 & 0.60 & 0.40 \\
Mean $P$ & $\mathrm{~m} \mathrm{yr}^{-1}$ & 1.6 & 0.6 & 0.4 \\
$\sigma P$ & $\mathrm{~m} \mathrm{yr}^{-1}$ & 0.7 & 0.2 & 0.1 \\
$\Delta$ ELA for $\sigma P$ & $\mathrm{~m}$ & -130 & -136 & -554 \\
Mean $S$ & $\mathrm{~W} \mathrm{~m}^{-2}$ & 283 & 358 & 311 \\
$\sigma S$ & $\mathrm{~W} \mathrm{~m}^{-2}$ & 10 & 9 & 9 \\
$\Delta$ ELA for $\sigma S$ & $\mathrm{~m}^{\circ}$ & 78 & 69 & 81 \\
Mean RH & $\%$ & 89 & 45 & 58 \\
$\sigma \mathrm{RH}$ & $\%$ & 2 & 5 & 4 \\
$\Delta$ ELA for $\sigma \mathrm{RH}$ & $\mathrm{m}$ & 2 & 3 & -11 \\
Mean $V$ & $\mathrm{~m} \mathrm{~s}^{-1}$ & 1.6 & 1.4 & 1.1 \\
$\sigma V$ & $\mathrm{~m} \mathrm{~s}^{-1}$ & 0.4 & 0.6 & 0.7 \\
$\Delta$ ELA for $\sigma V$ & $\mathrm{~m}^{\circ}$ & 4 & 2 & -14 \\
Mean $T_{a}$ & ${ }^{\circ} \mathrm{C}$ & 15 & 17 & 16 \\
$\sigma T_{a}$ & ${ }^{\circ} \mathrm{C}$ & 0.7 & 1.6 & 1.1 \\
$\Delta$ ELA for anomalously & $\mathrm{m}$ & 225 & 265 & 210 \\
$\quad$ warm summers & & & & \\
\hline
\end{tabular}

tion increases. For example, in the Taklamakan desert and the high elevation regions of the interior of the Tibetan Plateau and the western zone, warmest summers occur when cloud fraction is anomalously high because the increased longwave radiation is greater than the decreased shortwave radiation. The reverse is true over the more southerly regions, including the southern Himalayas, and the continental interior where clouds have a cooling tendency due to the increased albedo. While there is likely significant uncertainty in changes in cloud fraction and type in the reanalysis output, these results highlight the idea that glacier ELAs are sensitive to the influence of clouds on the shortwave and longwave radiation. This is perhaps not surprising since our analysis of the surface energy balance at the ELA suggests that net radiation dominates the energy balance at the surface (discussed in section 4).

A comparison of the pattern in $\Delta T_{\mathrm{amp}}$ (Fig. 12a) to $\Delta$ ELAs (Fig. 11c) indicates that $\Delta$ ELAs generally increase with increasing $\Delta T_{\mathrm{amp}}$. This illustrates the importance of the seasonal cycle in air temperature in calculating ablation as well as suggesting the value of a more complete sensitivity test, which calculates air temperatures independently at each time step rather than being constrained, as here, by prescribing $T_{\mathrm{amp}}$. This is discussed further in section 6 .

The pattern in ELA sensitivities is the result of both the magnitude in the change in climate and the differing sensitivity of the ELA to the dominant ablation process. Generally, for modern interannual variability, all melt regions are more sensitive to changes in temperature than precipitation. Changes in temperature are governed by changes in cloudiness and the amplitude in the seasonal cycle in air temperatures. The results suggest that ELAs in regions dominated by sublimation are more sensitive to changes in precipitation, relative humidity, and wind than those dominated by melt. These regions are also likely to be more sensitive to the model formulation than the regions dominated by melt. Given the sensitivity of the sublimation-dominated regions to numerous atmospheric quantities and model formulation, these regions are flagged as particularly complicated regions, for which simulations and predictions will be particularly hard.

\section{Summary and discussion}

\section{a. Summary}

A surface energy and mass balance model has been developed to explore the relationship between glacier equilibrium-line altitudes (ELAs) and climate at a regional scale. The model is applied to central Asia because of its wide range of climatic conditions.

We have shown that the model captures the pattern in absolute ELAs quite well, the seasonal cycle in energy balance terms are comparable to studies on individual glaciers in central Asia, and the proportionality factor relating melt to positive degree days (calculated using the surface energy balance and mass balance model) is within the range of those reported for individual glaciers within the area (Calanca and Heuberger 1990; Kayastha et al. 1999, 2003; Zhang et al. 2006). In addition, the reasonable variations in model parameters do not significantly influence the sensitivity of the ELA to changes in climate (supplemental appendix B). These results together suggest that the SEMB model performs well and is capable of capturing the sensitivity of ELAs to a change in climate at a regional scale.

With this model in hand, we were able to address the two questions posed in the introduction of this paper: 1) Can we understand the relative importance of accumulation and ablation in controlling mass balance of glaciers at regional scales and 2) how do the observed patterns of glacier response reflect regional changes in climate? We summarize our main conclusions in the context of these two questions, with an emphasis on the 

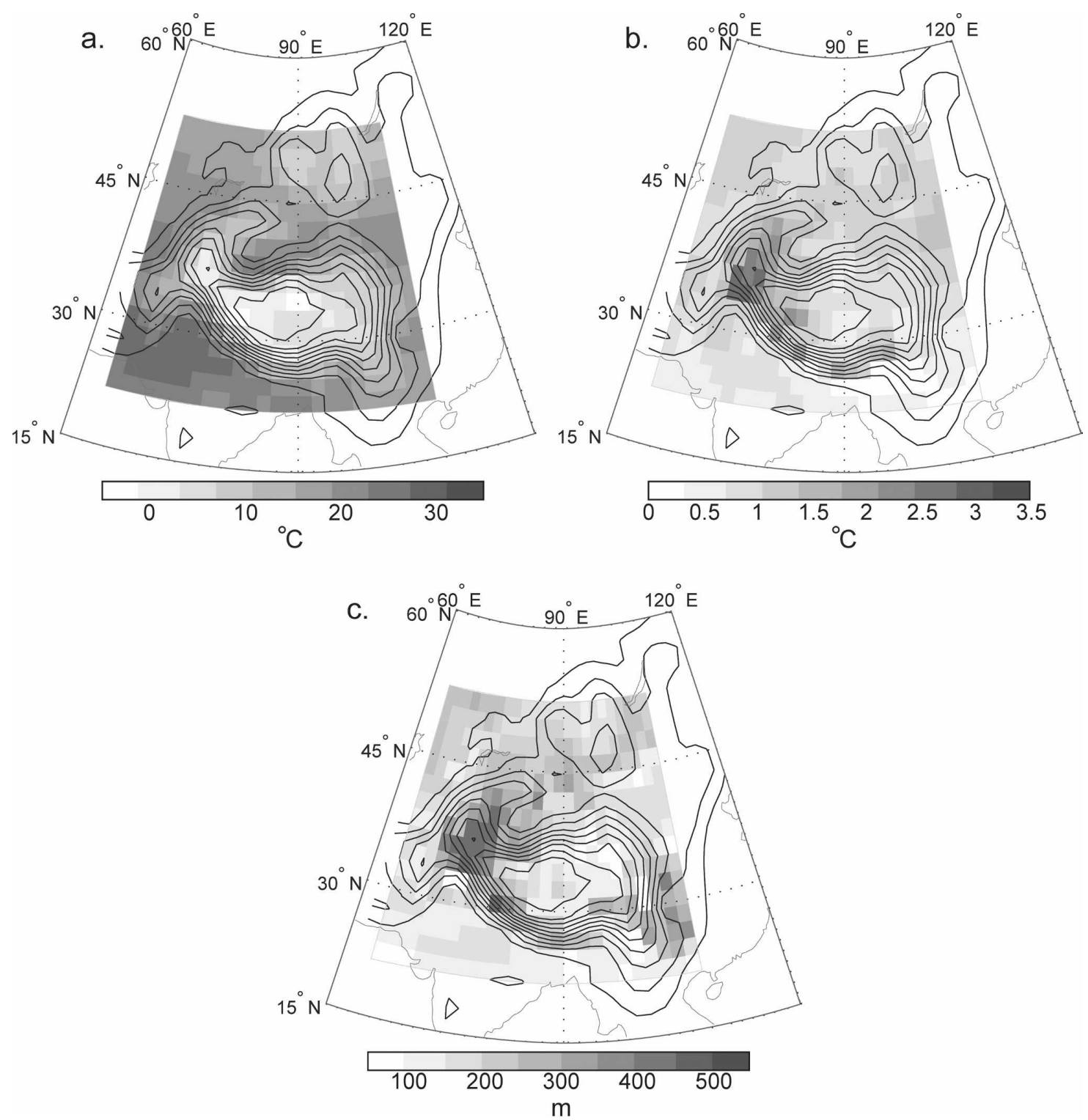

FIG. 11. (a) Mean summertime (JJA) surface air temperature $\left({ }^{\circ} \mathrm{C}\right)$, (b) standard deviation in summertime air temperature $\left({ }^{\circ} \mathrm{C}\right)$, and (c) $\triangle$ ELA for mean change in atmospheric variables when summertime temperatures are one standard deviation above the mean $(\mathrm{m})$; 500-m contour interval; zero contour not shown. Coastlines are in gray.

importance of the dominant ablation mechanism in answering both questions.

First, the spatial patterns in climate across central Asia produce a spatial pattern in the dominant ablation process. The pattern in ablation process is determined by the pattern in accumulation. In particular, where precipitation is low, ablation at the ELA is dominated by sublimation. Conversely, where precipitation is high, ablation at the ELA is dominated by melt and surface runoff.

Second, the ELA sensitivity to changes in climate is strongly tied to the dominant ablation process. In re- gions dominated by melt, the ELA is far more sensitive to ablation than accumulation. The change in ELA for anomalously warm summers in all regions is governed by changes in cloud fraction (and the associated changes in shortwave and longwave radiation) and the amplitude in the seasonal cycle in air temperature. Sublimation regions, however, are far more sensitive to changes in precipitation than to changes in ablation. Additionally, ELAs in sublimation-dominated regions are more sensitive to changes in relative humidity and wind speed than are ELAs in melt-dominated regions.

There is a narrow transition of only one or two re- 

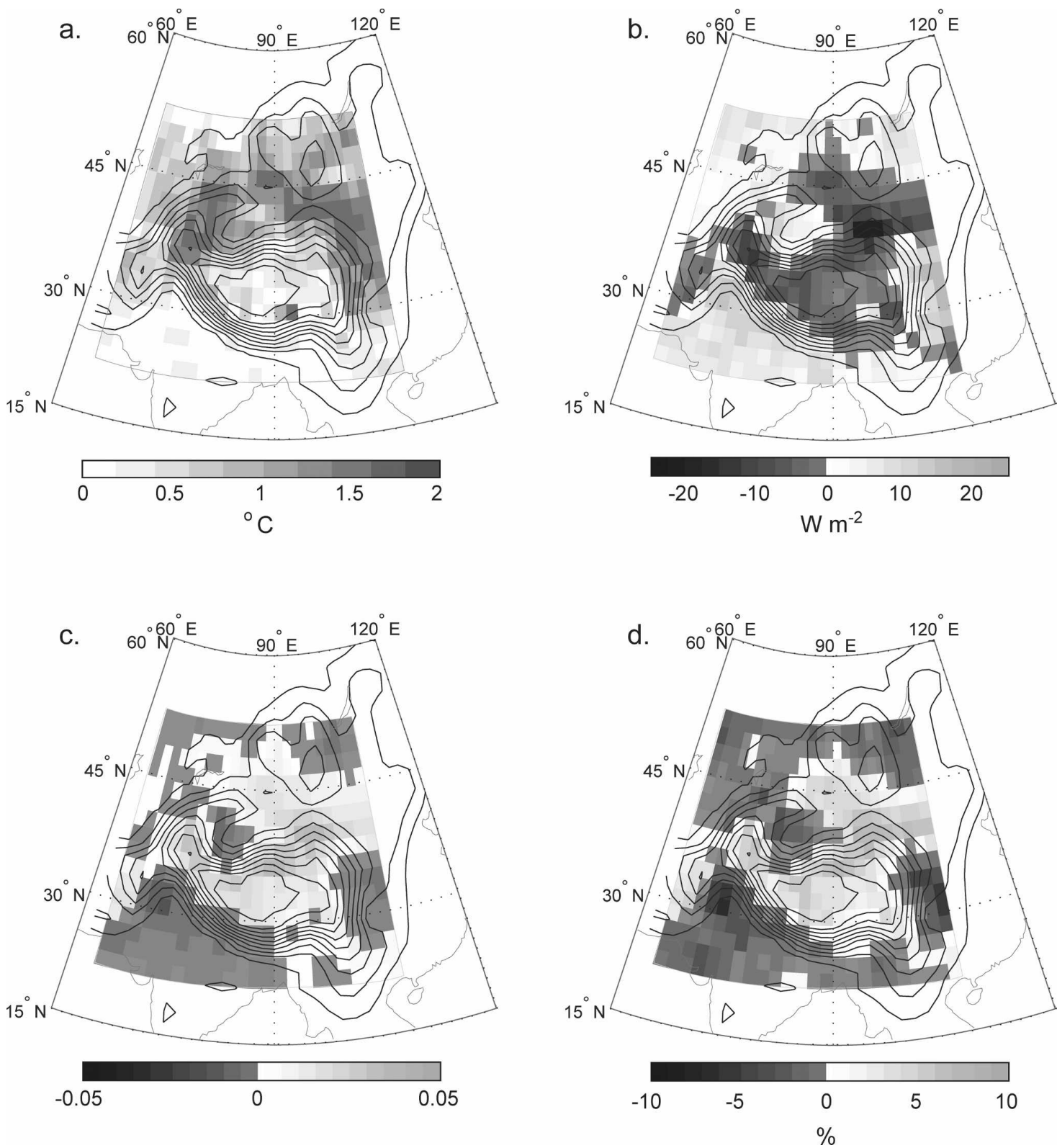

FIG. 12. The change for anomalously warm summers minus average summers: (a) amplitude in the seasonal cycle of air temperature $\left({ }^{\circ} \mathrm{C}\right),(\mathrm{b})$ incident shortwave radiation at the surface $\left(\mathrm{W} \mathrm{m}^{-2}\right)$, (c) downwelling longwave radiation constant $\left(C_{1}\right)$, and (d) cloud fraction (\%); 500-m contour interval; zero contour not shown. Coastlines are in gray.

analysis grid points between the sublimation-dominated and melt-dominated areas. This suggests ELA sensitivity in those transitional regions can quickly change in response to small changes in climate, illustrated in Fig. 6. Glaciers in these regions are close to a threshold where a small change in climate would result in rapid growth or demise of the glacier. Further sensitivity tests focused specifically on these regions would give insights into likely climates where glaciers are close to a threshold and the magnitude of climate changes required to push these glaciers from sublimation- to melt-dominated regimes, or vice versa.

\section{b. Discussion}

This study developed a framework capable of assessing the sensitivity of ELAs to changes in climate at a regional scale and at a first-order level of detail. Importantly, we have demonstrated that, for the level of the approach, uncertainty in model parameters and climate variables will not change the main conclusions. 
For example, precipitation in the Himalayas is known to vary significantly on spatial scales as short as $\sim 10 \mathrm{~km}$ (e.g., Anders et al. 2006), which cannot be captured here. It is conceivable that the magnitude in total precipitation and interannual precipitation variability in the reanalysis output could be off by a factor of 2 or more. Regardless, regions of high precipitation will be dominated by melt, and the energy balance at the surface will be dominated by radiative fluxes. We therefore do not anticipate the regional-scale answers to change.

What we have explored in this study can be regarded as the tendency of the climatic forcing on a regional scale. Any single glacier will be susceptible to numerous local factors, and may respond differently to climate than the larger-scale patterns would suggest. Capturing ELA sensitivities at smaller spatial scales would require a higher level of accuracy in the driving terms and ELA model than the current model formulation allows. For example, typical latent heat flux due to melt percolation and refreeze is around $10-20 \mathrm{~W} \mathrm{~m}^{-2}$. A change in albedo equal to 0.1 would result in a change in the absorbed shortwave radiation of the same order magnitude. Thus a model capable of higher accuracy would necessarily include all variables that would have a similar or greater influence on the energy balance as albedo variations. An atmospheric column model with internally derived snowpack would be capable of this level of detail. The next logical step to this study is to apply such a model to selected grid points within the larger region of interest here and to test the sensitivity of the ELAs at smaller scales. This would give insight into how different the sensitivity of any single glacier may be within the larger regions. It is not necessarily true, however, that the additional model complexity would produce more accurate answers.

There are many potential applications of the SEMB model. First, as we have shown, it can be used to ascertain the relative importance of sublimation versus melt and to test the sensitivity of glaciers to possible changes in climate at a regional scale anywhere in the world. Care must be taken to be sure that the model parameters chosen are appropriate for the region of interest. Second, the model can be used to test the tendency of the ELA to changes in forcings, such as changes in $\mathrm{CO}_{2}$ or orbitally induced changes in solar insolation. For example, we use this same model to calculate changes in ELA between present day and the mid-Holocene (when incoming solar insolation was at a relative maximum) and to reconcile the pattern in ELA changes with the changes in climate in central Asia (RU). The model can also be used to determine what atmospheric variables have contributed most to the re- gional changes in ELA seen around the globe over the last century.

Numerous studies have focused on diagnosing the response of glaciers to changes in climate. The framework developed in this study extends previous work by revealing regional patterns in the climate-driven dependencies of glaciers. By applying the model to modern interannual climate variability, we were able to determine the patterns of ELA sensitivity across the vastly differing climates across central Asia and diagnose why those patterns emerge. The sensitivity of ELAs to modern interannual climate variability can be used as an analog for understanding past changes in glacier mass balance, as well as a predictor of the response of glaciers to future changes in climate. For example, the analysis of modern interannual climate variability provides insight into the magnitude of climate changes required by the paleoclimate data and highlights which climate variables are likely to be the most important predictors of the fate of glaciers under global-warming conditions. Importantly, for both past and future climate scenarios, the inevitable fact of patterns in climate change means that a rich structure to the patterns of glacier response should be anticipated as well.

Acknowledgments. We thank David Battisti, Alan Gillespie, and Eric Steig for many insightful discussions that lead to the exposition of this paper, as well as their valuable suggestions on earlier drafts of the manuscript. We are also very thankful to Harvey Greenburg for making Fig. 4. We thank two anonymous reviewers for reviews that greatly improved the paper. Gerard Roe acknowledges support from NSF Grants 0409884 and 0507708

\section{REFERENCES}

Anders, A., G. Roe, B. Hallet, D. Montgomery, N. Finnegan, and J. Putkonen, 2006: Spatial patterns of precipitation and topography in the Himalaya. Tectonics, climate, and landscape evolution: Geological Society of America Special Paper 398, S. D. Willett et al., Eds., Geological Society of America, 39-53.

Bradley, R. S., 2000: Past global changes and their significance for the future. Quat. Sci. Rev., 19, 391-402.

Braithwaite, R. J., 1995: Positive degree-day factors for ablation on the Greenland ice-sheet studied by energy-balance modeling. J. Glaciol., 41, 153-160.

— Y Y. Zhang, and S. C. B. Raper, 2003: Temperature sensitivity of the mass balance of mountain glaciers and ice caps as a climatological characteristic. Z. Gletscherkunde Glazialgeol., 38 (1), 35-61.

Calanca, P., and R. Heuberger, 1990: Glacial Climate Research in the Tianshan. Zürcher Geogrische Schriften, Vol. 39, ETH Geographical Institute, 60-72.

Casal, T. G. D., J. E. Kutzbach, and L. G. Thompson, 2004: 
Present and past ice-sheet mass balance simulations for Greenland and the Tibetan Plateau. Climate Dyn., 23, 407425.

Denton, G. H., and C. H. Hendy, 1994: Younger Dryas age advance of Franz-Josef glacier in the Southern Alps of New Zealand. Science, 264, 1434-1437.

Duguay, C. R., 1993: Radiation modeling in the mountainous terrain-Review and status. Mt. Res. Dev., 13, 339-357.

Fountain, A. G., K. J. Lewis, and P. T. Doran, 1999: Spatial climatic variation and its control on glacier equilibrium-line altitude in Taylor Valley, Antarctica. Global Planet. Change, 22, $1-10$.

Gillespie, A., and P. Molnar, 1995: Asynchronous maximum advances of mountain and continental glaciers. Rev. Geophys., 33, 311-364.

- S. Rupper, and G. Roe, 2003: Climatic interpretation from mountain glaciations in Central Asia. GSA Annual Meeting, Abstracts with Program, Seattle, WA, Geological Society of America, Vol. 35, 414

Grove, J. M., and R. Switsur, 1994: Glacial geological evidence for the medieval warm period. Climatic Change, 26, 143-169.

Hastenrath, S., 1994: Recession of tropical glaciers. Science, 265, $1790-1791$

Hoinkes, H., and R. Steinacker, 1975: Parameterization of climate-glacier-relation. Riv. Ital. Geofis. Sci. Affini, 1 (Suppl. I), 97-104.

Kalnay, E., and Coauthors, 1996: The NCEP/NCAR 40-Year Reanalysis Project. Bull. Amer. Meteor. Soc., 77, 437-471.

Kaser, G., D. R. Hardy, R. Molg, R. S. Bradley, and R. M. Hyera, 2004: Modern glacier retreat on Kilimanjaro as evidence of climate change: Observations and facts. Int. J. Climatol., 24, 329-339.

Kaufman, D. S., S. C. Porter, and A. R. Gillespie, 2004: Quaternary alpine glaciation in Alaska, the Pacific Northwest, Sierra Nevada, and Hawaii. The Quaternary Period in the United States, Developments in Quaternary Science, A. R. Gillespie, S. C. Porter, and B. F. Atwater, Eds., Elsevier Press, 77-103.

Kayastha, R. B., T. Ohata, and Y. Ageta, 1999: Application of a mass-balance model to a Himalayan glacier. J. Glaciol., 45, 559-567.

_- Y. Ageta, M. Nakawo, K. Fujita, A. Sakai, and Y. Matsuda, 2003: Positive degree-day factors for ice ablation on four glaciers in the Nepalese Himalayas and Qinghai-Tibetan Plateau. Bull. Glaciol. Res., 20, 29-40.
Kessler, M. A., R. S. Anderson, and G. M. Stock, 2006: Modeling topographic and climatic control of east-west asymmetry in Sierra Nevada glacier length during the Last Glacial Maximum. J. Geophys. Res., 111, F02002, doi:10.1029/ 2005JF000365.

Kistler, R., and Coauthors, 2001: The NCEP-NCAR 50-Year Reanalysis: Monthly means CD-ROM and documentation. Bull. Amer. Meteor. Soc., 82, 247-267.

Lowell, T. V., and Coauthors, 1995: Interhemispheric correlation of late Pleistocene glacial events. Science, 269, 1541-1549.

Molg, T., and D. R. Hardy, 2004: Ablation and associated energy balance of a horizontal glacier surface on Kilimanjaro. $J$. Geophys. Res., 109, D16104, doi:10.1029/2003JD004338.

Oerlemans, J., 2005: Extracting a climate signal from 169 glacier records. Science, 308, 675-677.

Ohmura, A., 2001: Physical basis for the temperature-based meltindex method. J. Appl. Meteor., 40, 753-761.

Paterson, W., 1999: The Physics of Glaciers. Pergamon/Elsevier, $480 \mathrm{pp}$.

Plummer, M., and F. Phillips, 2003: A 2-D numerical model of snow/ice energy balance and ice flow for paleoclimatic interpretation of glacial geomorphic features. Quat. Sci. Rev., 22, 1389-1406.

Porter, S. C., 1975: Equilibrium-line altitudes of late Quaternary glaciers in Southern Alps, New Zealand. Quat. Res., 5, 27-47.

_ 1977: Present and past glaciation threshold in the Cascade Range, Washington, USA: Topographic and climatic controls, and paleoclimatic implications. J. Glaciol., 18, 101-116. , and G. Orombelli, 1985: Glacier contraction during the middle Holocene in the western Italian Alps - Evidence and implications. Geology, 13, 296-298.

Raup, B. H., A. Racoviteanu, S. J. S. Khalsa, C. Helm, R. Armstrong, and Y. Arnaud, 2007: The GLIMS geospatial glacier database: A new tool for studying glacier change. Global Planet. Change, 56, 101-110.

Wagnon, P., J. E. Sicart, E. Berthier, and J. P. Chazarin, 2003 Wintertime high-altitude surface energy balance of a Bolivian glacier, Illimani, $6340 \mathrm{~m}$ above sea level. J. Geophys. Res., 108, 4177, doi:10.1029/2002JD002088.

Zhang, Y., L. Shiyin, and D. Yongjian, 2006: Observed degree-day factors and their spatial variation on glaciers in western China. Ann. Glaciol., 43, 301-306. 